\title{
Telmisartan activates endogenous peroxisome proliferator-activated receptor- $\delta$ and may have anti-fibrotic effects in human mesangial cells
}

\author{
Daisuke Mikami $^{1}$, Hideki Kimura ${ }^{1,2}$, Kazuko Kamiyama ${ }^{1}$, Kunio Torii ${ }^{2}$, Kenji Kasuno ${ }^{1}$, Naoki Takahashi ${ }^{1}$, \\ Haruyoshi Yoshida $^{3}$ and Masayuki Iwano ${ }^{1}$
}

Telmisartan, an angiotensin II receptor type 1 blocker (ARB), was recently reported to promote lipolysis in mice by acting as a peroxisome proliferator-activated receptor (PPAR)- $\delta$ activator, although in clinical studies, it has also been recognized to activate PPAR- $\gamma$ as a major cause of its pleiotropic actions. The aim of this study was to investigate whether telmisartan activates endogenous PPAR- $\delta$ and thereby exerts anti-fibrotic effects in human mesangial cells (HMC). Immunohistochemical analysis of human renal biopsy specimens revealed that PPAR- $\delta$ protein was detected in the HMC of glomeruli with moderately proliferative changes. In the HMC, both GW0742, an authentic PPAR- $\delta$ agonist, and telmisartan enhanced PPAR response element (PPRE)-luciferase activity dose dependently, and these increases were blunted by GSK0660, a specific PPAR- $\delta$ antagonist, but not by GW9662, a PPAR- $\gamma$ antagonist. Telmisartan also upregulated the expression of PPAR- $\delta$ target genes related to fatty acid oxidation; that is, heart type-fatty acid-binding protein and uncoupling protein-2. These effects were inhibited by both PPAR- $\delta$ antagonism and PPAR- $\delta$ gene silencing. Transforming growth factor- $\beta 1$ (TGF- $\beta 1$ ) increased the expression of plasminogen activator inhibitor-1 (PAI-1), TGF- $\beta 1$ and collagen IV. The PAI- 1 expression was mediated, at least in part by the phosphorylation of extracellular signal-regulated kinases (ERKs). Telmisartan suppressed TGF- $\beta 1$-stimulated PAI-1 and collagen IV expression and ERK phosphorylation, and these effects were weakened by PPAR- $\delta$ antagonism, whereas eprosartan, a non-PPAR activating ARB, did not affect TGF-p1-stimulated PAI-1 expression. These results indicate that in HMC telmisartan activates endogenous PPAR- $\delta$ and may prevent TGF- $\beta 1$-induced fibrotic changes by reducing ERK phosphorylation in a PPAR- $\delta$-dependent manner, and thus, might be useful for treating hypertensive patients with renal and metabolic disorders. Hypertension Research (2014) 37, 422-431; doi:10.1038/hr.2013.157; published online 19 December 2013

Keywords: ERK pathway; plasminogen activator inhibitor-1; TGF-beta 1

\section{INTRODUCTION}

Peroxisome proliferator-activated receptors (PPARs) are liganddependent transcription factors belonging to the nuclear hormone receptor superfamily. PPAR includes three different subtypes designated as PPAR- $\alpha$, PPAR- $\delta$ and PPAR- $\gamma$, which are characterized by distinct expression patterns and biological functions. ${ }^{1}$ PPAR- $\alpha$ is highly expressed in the liver, activated by long-chain fatty acids, and involved in lipid metabolism, whereas PPAR- $\gamma$ is predominantly expressed in adipose tissue; activated by synthetic agonists, for example, anti-diabetic thiazolidinediones (TZD) such as pioglitazone; and has a pivotal role in promoting adipogenesis and increasing insulin sensitivity. PPAR- $\delta$ is widely expressed in various tissues including adipose tissue, muscle tissue and kidneys. Interestingly, PPAR- $\delta$ activation by synthetic agonists augments fatty acid oxidation in muscle and thermogenesis in adipose tissue, resulting in enhanced endurance performance and retarded weight gain. ${ }^{2}$ Furthermore, PPAR has been demonstrated to have antiinflammatory and anti-fibrotic effects. ${ }^{1,3-5}$ For example, PPAR- $\alpha$ activation inhibits basal and interleukin-1-stimulated C-reactive protein production in hepatocytes, ${ }^{6}$ and PPAR- $\gamma$ agonists reduce tumor necrosis factor- $\alpha$, interleukin-1 and interleukin- 6 production in monocytes. ${ }^{7}$ Intriguingly, accumulating evidence suggests that PPAR- $\delta$ activation also suppresses inflammatory responses in rodents, ${ }^{2,8}$ human keratinocytes ${ }^{9}$ and skeletal muscle cells. ${ }^{10}$

Angiotensin II receptor type I blockers (ARBs) are currently widely used in the treatment of hypertension and hypertension-associated cardiovascular and renal diseases. ${ }^{11}$ In addition to their important roles as anti-hypertensive drugs, ARB has also been reported to have metabolic effects. ${ }^{12}$ For example, some ARB lowers the risk of type 2 diabetes ${ }^{12}$ and improve insulin sensitivity in rodents ${ }^{13}$ and humans. ${ }^{14}$

${ }^{1}$ Division of Nephrology, Department of Medicine, Faculty of Medical Sciences, School of Medicine, University of Fukui, Fukui, Japan; ${ }^{2}$ Department of Clinical Laboratories and Nephrology, University of Fukui Hospital, Fukui, Japan and ${ }^{3}$ Division of Nephrology, Department of Internal Medicine, Obama Municipal Hospital, Obama, Fukui, Japan Correspondence: Dr H Kimura, Department of Clinical Laboratories and Nephrology, University of Fukui Hospital, 23-3 Matsuoka-shimoaizuki, Eiheiji, Yoshida, Fukui 910-1193, Japan.

E-mail: hkimura@u-fukui.ac.jp

Received 16 April 2013; revised 19 September 2013; accepted 14 November 2013; published online 19 December 2013 
Recently, telmisartan, an ARB that is highly selective for the angiotensin-II type I receptor, was demonstrated to activate PPAR$\gamma$, thereby inducing adipogenesis ${ }^{15,16}$ and increasing insulin sensitivity in rodent tissues, ${ }^{16}$ and these effects were probably due to its structural similarity to pioglitazone, a major TZD. ${ }^{16,17}$

As is the case with authentic PPAR- $\gamma$ activators, telmisartan reportedly exerts anti-inflammatory effects in a PPAR- $\gamma$-dependent manner both in vitro ${ }^{18,19}$ and in vivo ${ }^{20}$ and also improves insulin sensitivity in hypertensive patients. ${ }^{21}$ Nevertheless, a number of studies have shown that the anti-inflammatory effects of telmisartan are PPAR- $\gamma$ independent. ${ }^{22-24}$ Moreover, previous studies have reported differences between the pharmacological activities of telmisartan and authentic PPAR- $\gamma$ agonists, for example, TZD. Namely, telmisartan treatment did not result in body weight gain in animals ${ }^{16}$ or humans, ${ }^{25}$ whereas treatment with TZD occasionally induced body weight gain as an adverse effect. ${ }^{26}$ These unique features of telmisartan led to the recent findings that telmisartan prevents weight gain and obesity and improves insulin resistance of skeletal muscle via PPAR- $\delta$ activation in mice. ${ }^{27,28}$

Experimental $^{20,29,30}$ and clinical studies ${ }^{31,32}$ have revealed the renoprotective potential of telmisartan treatment. As it is possible that telmisartan is a dual activator of PPAR- $\delta$ and PPAR- $\gamma$, its inhibitory effects on inflammation and fibrosis in injured renal tissues might be due, in considerable part, to PPAR- $\delta$ activation as well as PPAR- $\gamma$ activation. However, the PPAR- $\delta$ activation induced by telmisartan and the ensuing modulation of inflammation have not been examined in human cells despite the worldwide use of telmisartan in clinical practice.

In the current study, we aimed to investigate whether telmisartan activates endogenous PPAR- $\delta$ and, if so, whether it also inhibits transforming growth factor- $\beta 1$ (TGF- $\beta 1$ )-induced fibrotic reactions via a PPAR- $\delta$-dependent pathway in human mesangial cells (HMC), which have a central role in glomerulosclerosis.

\section{METHODS}

\section{Materials}

GW0742 was purchased from Cayman Chemical Company (Ann Arbor, MI, USA). Telmisartan, pioglitazone, GW9662 and GSK0660 were purchased from SIGMA-Aldrich (St Louis, MO, USA). Eprosartan and aldosterone were purchased from Tronto Research Chemicals (North York, ON, Canada) and Acros Organics (Geel, Belgium), respectively. The Dual-Luciferase Reporter Assay System was purchased from Promega (Madison, WI, USA). Recombinant TGF- $\beta 1$ and PDGF-BB were purchased from R\&D Systems (Minneapolis, MN, USA). Polyclonal rabbit antibodies against human PPAR- $\delta$ and human $\beta$-actin (Abcam, Cambridge, UK), human phosphorylated extracellular signalregulated kinase 1/2 (pERK1/2; Thr202/Tyr204), human PPAR- $\gamma$, human collagen IV alpha2 (Santa Cruz Biotechnology, Santa Cruz, CA, USA) and ERK1/2 (Cell Signaling Technology, Boston, MA, USA) were used. Monoclonal mouse antibody against heart-type fatty acid-binding protein (H-FABP) (Hycult Biotechnology, Uden, The Netherlands) and horseradish peroxidaseconjugated anti-mouse and anti-rabbit immunoglobulins (Dako, Glostrup, Denmark) were also used.

\section{Mesangial cell cultures}

HMC were purchased as third passage cells from Lonza Walkersville (Walkersville, MD, USA). The cells (passages 4 through 5) were grown in MsGM (mesangial cell growth media) supplemented with $5 \%$ fetal bovine serum and $1 \mu \mathrm{g} \mathrm{ml}^{-1}$ gentamicin, in a humidified atmosphere containing $5 \% \mathrm{CO}_{2}$ and $18 \% \mathrm{O}_{2}$ at $37^{\circ} \mathrm{C}$. After HMC of between the fourth and fifth passage had been cultured to confluence, they were growth arrested in Dulbecco's modified Eagle's medium (DMEM) (Invitrogen, Carlsbad, CA, USA) supplemented with $0.5 \%$ fetal bovine serum (Invitrogen) for $24 \mathrm{~h}$, and the DMEM was renewed immediately before the stimulation experiments.
Telmisartan, pioglitazone, GW9662 and GSK0660 were prepared as stock solutions in dimethyl sulfoxide (Sigma-Aldrich), and eprosartan and aldosterone as a stock solution in ethanol. These reagents were further diluted to working concentrations in the cell incubation medium. The final concentration of dimethyl sulfoxide and ethanol in our experiments did not exceed $0.1 \%$. The vehicle $(0.1 \%$ dimethyl sulfoxide or $0.1 \%$ ethanol $)$ was added to the control samples.

\section{Cell proliferation assays}

Qualitative index of proliferating Cell viability was determined by XTT assay according to the manufacturer's protocol (Roche Applied Science, Mannheim, Germany). Briefly, HMC were seeded in 96-well plates at a density of $1 \times 10^{4}$ per well in MsGM for $24 \mathrm{~h}$ before drug treatment. When HMC reached $80 \%$ confluence, the culture medium was replaced with DMEM with 0.5\% BSA containing vehicle, PDGF-BB $\left(10 \mathrm{ng} \mathrm{ml}^{-1}\right)$, Telmisartan $(10 \mu \mathrm{M})$ or PDGF-BB plus Telmisartan at $37^{\circ} \mathrm{C}$ in $5 \% \mathrm{CO}_{2}$ for $24 \mathrm{~h}$. At the end of the 24 -h period, $50 \mu \mathrm{l}$ XTT labelling mixture was added to each well, and the plates were incubated for further $4 \mathrm{~h}$ at $37^{\circ} \mathrm{C}$ and $5 \% \mathrm{CO}_{2}$. The wavelength to measure absorbance of the formazon product was $490 \mathrm{~nm}$, and the reference wavelength was $650 \mathrm{~nm}$.

\section{Transient transfection of a PPAR response element-luciferase expression vector}

PPAR-induced transcriptional activity was evaluated via the transient transfection of an expression vector containing four copies of a consensus PPAR response element (PPRE), which was placed upstream of the TK-luciferase reporter (pPPRE-TK-Luc), as reported previously. ${ }^{33} \mathrm{HMC}$ were seeded in a 24 -well plate at a density of $5 \times 10^{4}$ cells per well and incubated in MsGM without antibiotics. The next day, the cells were transfected with $400 \mathrm{ng}$ of the pRL-TK control vector or $400 \mathrm{ng}$ of the pPPRE-TK-Luc using Lipofectamine 2000 (Invitrogen) and OPTI-MEN (Invitrogen). Four hours later, the transfection medium was replaced with DMEM containing 0.5\% BSA and then placed in a humidified atmosphere of $5 \% \mathrm{CO}_{2}$ and $95 \%$ air at $37^{\circ} \mathrm{C}$ for $24 \mathrm{~h}$, and the DMEM was renewed immediately before the stimulation experiments. Finally, the cells were lysed in lysis buffer, and the firefly luciferase and Renilla luciferase activity in the lysates were determined with a luminometer using the dual-luciferase reporter assay kit (Promega). All of the experiments were performed at least three times in triplicate, and the data were normalized to Renilla activity.

\section{TaqMan real-time PCR assay}

Total RNA was extracted from the cultured cells using a commercial instrument (MFX-2100, TOYOBO, Osaka, Japan) and a commercially available kit (MagExtractor -RNA-, TOYOBO). The cDNA synthesis was performed with a High Capacity cDNA Archive kit (Applied Biosystems, Foster City, CA, USA) according to the supplied protocol. TaqMan real-time RT-PCR was performed with a TaqMan ABI 7000 Sequence Detection System (Applied Biosystems) using TaqMan Universal PCR Master Mix (Applied Biosystems). Unlabelled specific primers and TaqMan MGB probes (6-FAM dye-labelled) from Applied Biosystems were used to detect human plasminogen activator inhibitor-1 (PAI-1) (assay ID: Hs00167155_m1), H-FABP (assay ID: Hs00269758_m1), human uncoupling protein-2 (UCP-2; assay ID: Hs01075227_m1), human TGF- $\beta 1$ (assay ID: Hs00998133_m1), human collagen IV alpha2 (assay ID: Hs01098873_ml) and human PPAR- $\delta$ (assay ID: Hs00987011_m1). A TaqMan human $\beta$-actin MGB (VIC dye-labelled) control reagent kit (Applied Biosystems, accession no: NM_001101) was used to detect human $\beta$-actin. After an initial $2 \mathrm{~min}$ at $50^{\circ} \mathrm{C}$ and $10 \mathrm{~min}$ at $95^{\circ} \mathrm{C}$, the samples were cycled 40 times at $95^{\circ} \mathrm{C}$ for $15 \mathrm{~s}$ and $60^{\circ} \mathrm{C}$ for $1 \mathrm{~min}$. The PAI- 1, H-FABP, TGF- $\beta 1$, PPAR- $\delta$ and $\beta$-actin cDNA templates were quantified separately using standard curves produced via the serial dilution of standard cDNA. The threshold cycle of each sample was converted to a standard cDNA dilution value (arbitrary units). For quantitative analysis, the H-FABP, UCP-2, PAI- 1 , TGF- $\beta 1$ and PPAR- $\delta$ cDNA content of each sample was normalized to the level of $\beta$-actin, a housekeeping gene. 


\section{Transfection of small-interfering RNA against PPAR- $\delta$}

Small-interfering RNA (siRNA) against PPAR- $\delta$ and control siRNA (a nontargeting siRNA) was purchased from Thermo Scientific Dharmacon (Lafayette, CO, USA). HMC ( $70 \%$ confluence) were transfected with the negative control siRNA or siRNA against PPAR- $\delta$ at a final concentration of $5 \mathrm{nmoll}^{-1}$ using the Lipofectamine RNAiMAX transfection reagent (Invitrogen) according to the manufacturer's instructions. After 48-h incubation, HMC that had been refreshed with DMEM were treated with or without telmisartan for an additional $24 \mathrm{~h}$ and then had their H-FABP mRNA and protein expression analyzed.

\section{Determination of human PAI-1 antigen concentrations}

The total concentration of PAI- 1 in each cell-culture supernatant was measured using a commercial analyser (STACIA; Mitsubishi Chemical Medience, Tokyo, Japan) and a commercially available immunoassay kit (LPIA-tPAI TEST; Mitsubishi Chemical Medience) according to a recently reported method. ${ }^{34}$ This method has a detection limit of $1.5 \mathrm{ng} \mathrm{ml}^{-1}$, and the intra- and interassay coefficients of variation were 1.4 and $5.8 \%$, respectively.

\section{Determination of H-FABP concentration}

The H-FABP concentrations of the HMC cell lysates were also determined using a commercially available ELISA kit (Hycult Biotechnology, Uden, The Netherlands) according to the manufacturer's instructions. The cell lysates (1:100 dilution) and standards were incubated for $1 \mathrm{~h}$, together with peroxidase-conjugated secondary antibodies in microtiter wells that had been coated with antibodies for human H-FABP. After the cells had been washed three times, tetramethylbenzidine was added, and color development was stopped by adding citric acid. The concentration of H-FABP in each total cell lysate was calculated using a linear calibration curve based on measured standard values. Each concentration was normalized to the amount of protein in the corresponding cell lysate, which was measured with the Bradford protein assay.

\section{Immunoblot analysis}

HMC were lysed in RIPA buffer containing phosphatase inhibitors (SIGMAAldrich). Ten micrograms of protein were separated on an $8 \%$ SDSpolyacrylamide gel and then electrophoretically transferred onto nitrocellulose membranes (Trans-Blot SD; Bio-Rad, Hercules, CA, USA). The membranes were blocked with Blocking One or Blocking One-P (Nacalai Tesque, Kyoto, Japan) in Tris-buffered saline (pH 8.0) containing $0.05 \%$ Tween-20 (TBS-T) at $37^{\circ} \mathrm{C}$ for $1 \mathrm{~h}$ and then incubated with anti-PPAR- $\delta$ (1:200 dilution), antiPPAR- $\gamma$ (1:200 dilution), anti-H-FABP (1:50 dilution), anti- $\beta$-actin (1:1000 dilution), anti-Collagen IV alpha2 (1:200), anti-ERK1/2 (1:1000 dilution) and anti-pERK1/2 (1:500 dilution) antibodies for $1 \mathrm{~h}$ at room temperature. Next, the membranes were incubated with appropriate horseradish peroxidaseconjugated secondary antibodies (1:1000 dilution) at room temperature for $1 \mathrm{~h}$. Finally, the secondary antibodies were visualized using the ECL detection system from Thermo Fisher Scientific (Pittsburg, PA, USA). The signal intensities of specific bands were quantified with a densitometer (Image Quant TL; GE Healthcare LK, Buckinghamshire, UK).

\section{Immunohistochemistry}

Ten renal biopsy samples were randomly selected from nineteen patients with biopsy-proven IgA nephropathy, who admitted to Fukui University Hospital between 2011 and 2012. Informed consent for this study was obtained from each patient. The characteristics of the patients selected are the following: 3 males and 7 females; age (mean \pm s.d.), $39.6 \pm 15.0$ years; serum Cr levels, $0.85 \pm 0.30 \mathrm{mg} \mathrm{dl}^{-1}$; urinary protein amounts, $0.96 \pm 0.80 \mathrm{~g} \mathrm{day}^{-1}$.

Four percent paraformaldehyde-fixed paraffin-embedded renal biopsy samples ( $2 \mu \mathrm{m}$ sections) from patients with kidney disease (who gave their written informed consent) were subjected to immunoperoxidase staining. Rabbit polyclonal antibody against PPAR- $\delta$ (working dilution: 1:250) was used as a primary antibody for determining the localization of PPAR- $\delta$. Positive staining was detected using the Envision kit/HRP (DAB) (Dako) according to the manufacturer's instructions.

\section{Histological assessments}

Two pathologists reviewed the slides separately. The extent of mesangial expansion including matrix accumulation and cell proliferation was scored semi-quantitatively on a 0 to 2 scale for each glomerulus ( 0 : no expansion, $1+$ : less than one-third of glomeruli, $2+$ : one-third to two-third of glomeruli). In severe and global sclerosis where the number of PPAR- $\delta$ producing mesangial cells markedly decreases, PPAR- $\delta$ staining was inevitably diminished. Therefore, severe or global sclerotic lesions were excluded from the analysis of mesangial expansion. Mesangial PPAR- $\delta$ staining was scored on a 0 to 3 scale for each glomerulus ( 0 , no lesion present; $1+,<30 \%$ of the mesangial area; $2+, 30-60 \%$ of the mesangial area; $3+,>60 \%$ of the mesangial area). Then, the average score per slide was expressed as the sum of the grades of each glomerulus divided by the total number of glomeruli.

\section{Statistical analyses}

All samples were run in duplicate for protein analysis or triplicate for mRNA analysis, and the results are presented as the mean and standard deviation ( \pm s.d.). All experiments were performed at least three times. The Mann-Whitney test was used to evaluate the significance of differences between two groups. The differences in mesangial expansion score between two groups were evaluated by ANCOVA with several clinical variables used as covariates. The statistical significance of the differences among more than two groups was examined using one-way ANOVA followed by Scheffe's post hoc test. $P$-values of $<0.05$ were considered as statistically significant.

\section{RESULTS}

Immunohistolocalization of PPAR- $\delta$ protein in human kidneys PPAR- $\delta$ protein staining was identified predominantly in the nuclei of mesangial cells as well as podocytes of glomeruli in renal biopsy samples from patients with IgA nephropathy showing minor to moderately proliferative glomerulonephritis (Figures $1 \mathrm{a}-\mathrm{d}$ ), while it was obviously decreased in advanced fibrosis of glomeruli ( $\operatorname{IgA}$ nephropathy; data not shown). The intensity of PPAR- $\delta$ expression was moderately greater in moderately proliferative lesions of mesangial area (Figures 1c and d) than in minor proliferative ones (Figures $1 \mathrm{a}$ and $\mathrm{b})$. The patient group of IgA nephropathy $(n=10)$ was divided into two subgroups according to the median value (1.0) of scores for mesangial expansion and proliferation. Groups with the scores of less than 1.0 or with those equal to 1.0 or more were defined as low or high score group, respectively. The two groups differed in age, although no differences in gender distribution, serum $\mathrm{Cr}$ levels or urinary protein levels were found. The scores of mesangial PPAR- $\delta$ staining were significantly higher in the high score group than in the low score group even after adjustment for age (1.54 \pm 0.52 vs $0.74 \pm 0.40, P<0.01$, Figure 1e). These results indicated that PPAR$\delta$ expression was upregulated in mildly to moderately proliferative glomerulonephritis observed in IgA nephropathy.

\section{Telmisartan activates endogenous PPAR- $\delta$ protein in HMC} Immunoblot analyses showed that PPAR- $\delta$ and PPAR- $\gamma$ proteins were present as single bands of about 52 and $57 \mathrm{kDa}$, respectively, in the whole HMC lysates (Figure 2a). As for the transcriptional activity of PPAR, GW0742, an authentic PPAR- $\delta$ agonist, enhanced PPREluciferase expression in the HMC, and this enhancement was significantly inhibited by GSK0660, a specific antagonist of PPAR- $\delta$, in a dose-dependent manner (Figure 2b), but not by GW9662, a specific antagonist of PPAR- $\gamma$ (Figure 2c). While pioglitazone, an authentic PPAR- $\gamma$ agonist, also increased the PPRE-luciferase activity of the HMC, which was significantly inhibited by GW9662 in a dose-dependent manner (Figure 2d), but not by GSK0660 (Figure 2e). These results demonstrated that functional PPAR- $\delta$ and PPAR- $\gamma$ proteins exist in HMC. In turn, we examined whether 
a

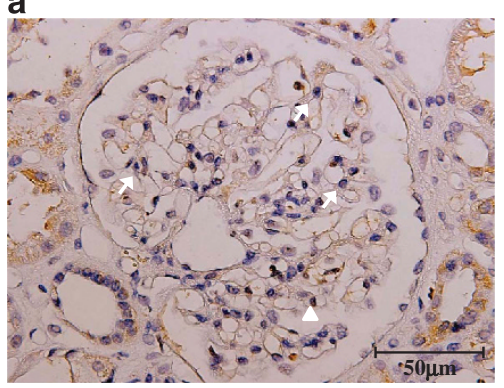

c

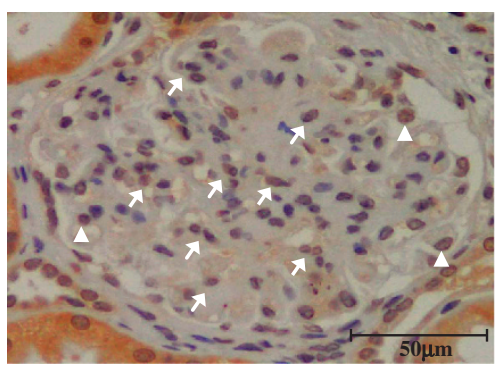

b

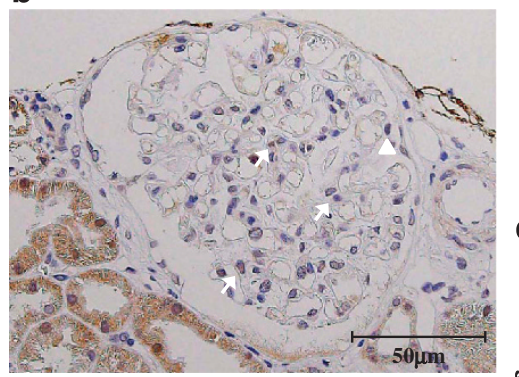

d

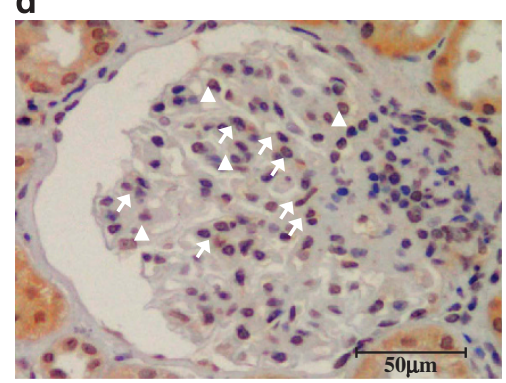

e

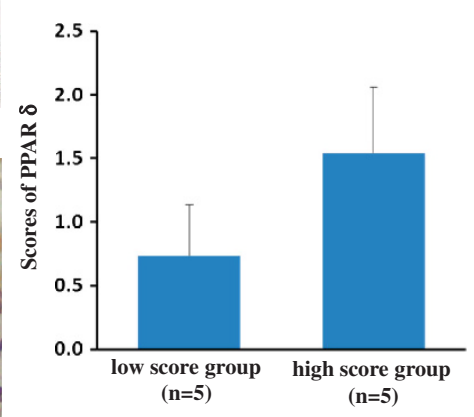

Figure 1 Immunohistochemical analyses of peroxisome proliferator-activated receptor (PPAR)- $\delta$ protein expression in renal biopsy specimens obtained from patients that were diagnosed with proliferative glomerulonephritis (IgA nephropathy, $n=10$ ). PPAR- $\delta$ staining was observed predominantly in the nuclei of mesangial cells (white arrows) or podocytes (white arrowheads) (a-d). The staining intensity appeared to be greater in glomeruli with mild-to-moderate mesangial proliferation (c, d) than in those with minor mesangial proliferation (a, b). Original magnification: $\times 200$. Mesangial expansion and PPAR- $\delta$ staining were evaluated in renal biopsy samples from 10 patients with biopsy-proved IgA nephropathy. The patients were divided into two groups according to the median value (1.0) of mesangial expansion scores. Low and high score groups indicate ones with the submedian and supramedian score. The scores of mesangial PPAR- $\delta$ staining were significantly higher in the high score group than in the low score group (e). ${ }^{*} P<0.01$ compared with the indicated group according to ANCOVA.

telmisartan increases PPRE-luciferase activity. Treatment with telmisartan significantly amplified the PPRE-luciferase activity of the HMC by 1.3 -fold and by 2.4-fold at concentrations of 1 and $10 \mu \mathrm{moll}^{-1}$, respectively (Figure 2f). Furthermore, the increase in PPRE-luciferase activity induced by telmisartan $\left(10 \mu \mathrm{moll}^{-1}\right)$ was completely inhibited by GSK0660 in a dose-dependent manner (Figure 2g), but not by GW9662 (Figure 2h). Consequently, these findings indicated that telmisartan activates endogenous PPAR- $\delta$ in HMC.

\section{Telmisartan induces H-FABP and UCP-2 expression via a PPAR- $\delta$-dependent pathway}

Next, we examined whether the activation of PPAR- $\delta$ by telmisartan induces the expression of its target genes, which are enhancers of fatty acid oxidation; that is, H-FABP and UCP-2, in HMC. Immunoblot analysis detected H-FABP in the HMC whole-cell lysate as a single $13 \mathrm{kDa}$ band (data not shown). The H-FABP concentrations of the cell lysates were measured by ELISA. In the HMC, 24-h treatment with GW0742 significantly increased H-FABP expression by 1.8 -fold at the mRNA level and by 1.4-fold at the protein level compared with no treatment (Figures $3 \mathrm{a}$ and $\mathrm{b}$ ). These increases were significantly inhibited by GSK0660 in a dose-dependent manner (Figures 3a and b). Similarly, telmisartan also increased H-FABP mRNA expression by 1.7 -fold and H-FABP protein expression by 1.4 -fold, both of which were inhibited by GSK0660 in a dose-dependent manner (Figures $3 \mathrm{c}$ and $\mathrm{d}$ ). Moreover, we conducted PPAR- $\delta$ gene silencing in HMC using siRNA in order to determine whether the telmisartaninduced H-FABP expression was dependent on PPAR- $\delta$. As a result, we detected marked decreases in PPAR- $\delta$ mRNA and protein expression in the HMC treated with siRNA against PPAR- $\delta$
(Figure 3e). The transient transfection of HMC with PPAR- $\delta$ siRNA significantly attenuated the telmisartan-induced expression of H-FABP mRNA by about $65 \%$ (Figure 3f). In addition, telmisartan as well as GW0742 enhanced the UCP-2 mRNA levels of the cells in a PPAR- $\delta$-dependent manner (Figures $3 g$ and $h$ ). These findings suggest that in HMC telmisartan induced the expression of PPAR- $\delta$ target genes related to fatty acid oxidation via PPAR- $\delta$.

On the basis of the above findings, it seems undeniable that telmisartan activates endogenous PPAR- $\delta$ and augments its transcriptional functions in HMC.

Telmisartan decreases TGF- $\beta 1$-stimulated expression of pro-fibrotic genes in a PPAR- $\delta$-dependent manner in HMC

PAI-1 mRNA expression was induced by TGF- $\beta 1$ at doses ranging from 10 to $1000 \mathrm{pg} \mathrm{ml}^{-1}$, reaching a plateau of twofold at $500 \mathrm{pg} \mathrm{ml}^{-1}$ (detailed data not shown). Since the half-maximal effect of TGF- $\beta 1$ was observed at a concentration of $25 \mathrm{pg} \mathrm{ml}^{-1}$, we used this concentration to evaluate the effect of telmisartan on TGF- $\beta 1$ induced PAI- 1 expression. TGF- $\beta 1\left(25 \mathrm{pg} \mathrm{ml}^{-1}\right)$ increased PAI-1 mRNA expression by 1.5 -fold at $6 \mathrm{~h}$ and PAI- 1 protein expression by 1.4 -fold at $24 \mathrm{~h}$ (Figures $4 \mathrm{a}$ and b). Telmisartan $\left(10 \mu \mathrm{moll}^{-1}\right)$ significantly reduced TGF- $\beta 1$-stimulated PAI- 1 expression by about $30 \%$ at the mRNA level and by $40 \%$ at the protein level (Figures $4 \mathrm{a}$ and b). Furthermore, simultaneous treatment with a specific PPAR- $\delta$ antagonist, GSK0660 $\left(1 \mu \mathrm{moll}^{-1}\right)$, almost completely abrogated the inhibitory effect of telmisartan on PAI-1 expression (Figures $4 \mathrm{a}$ and b). Similarly, TGF- $\beta 1$ significantly induced the expression of TGF- $\beta 1$ (Figure 4c), connective tissue growth factor (data not shown) and Collagen IV alpha2, one of the major components for glomerular sclerosis (Figure 4d), at the mRNA level. 
a

$\operatorname{PPAR} \delta(52 \mathrm{kDa})$

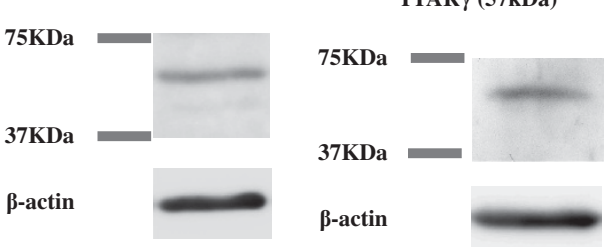

b

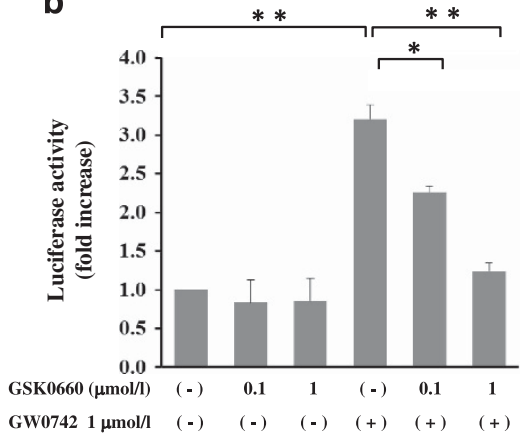

c

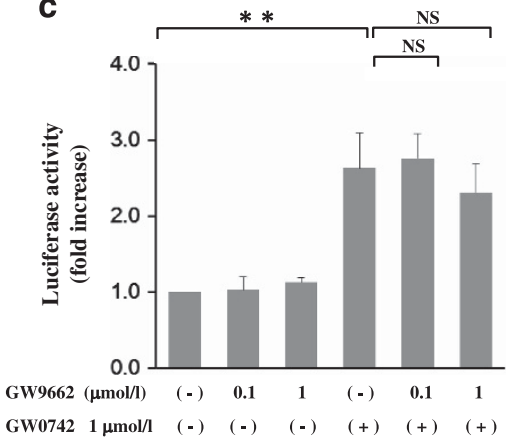

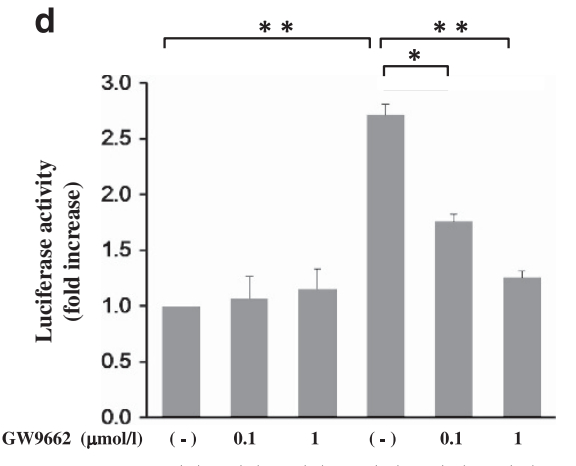

Pioglitazone $3 \mu \mathrm{mol} / / \mathrm{l} \quad(-) \quad(-) \quad(-) \quad(+) \quad(+) \quad(+)$

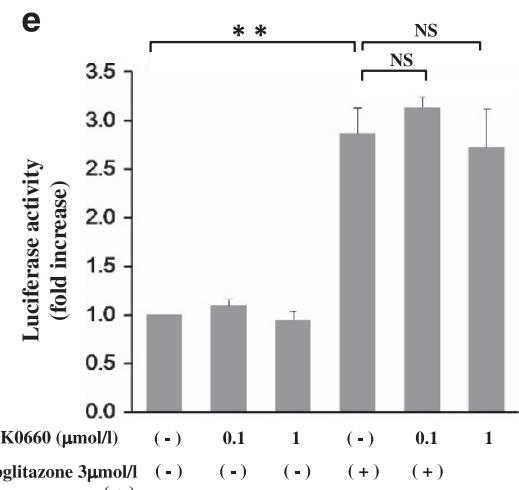

$(+)$ f

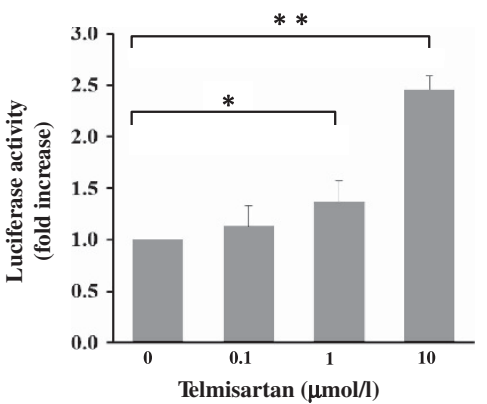

g

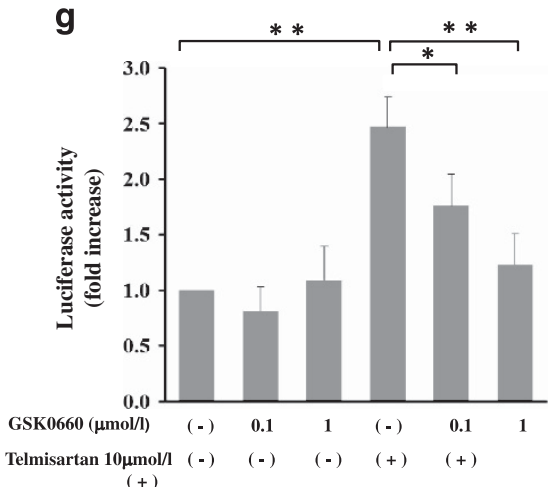

h

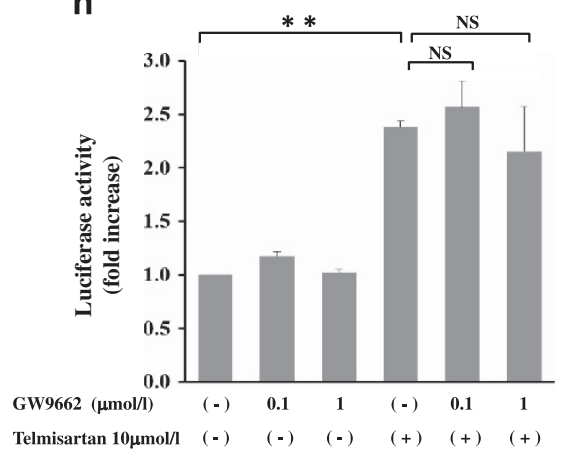

Figure 2 Presence of functional peroxisome proliferator-activated receptor (PPAR)- $\delta$ and PPAR- $\gamma$ and telmisartan-induced activation of endogenous PPAR- $\delta$ in human mesangial cells (HMC). (a) In whole-cell lysates from confluent HMC, PPAR- $\delta$ and PPAR- $\gamma$ protein was detected by immunoblotting. (b-h) HMC were transfected with an expression vector containing four copies of a consensus PPAR response element placed upstream from the TK-luciferase reporter. The cells were then incubated for $24 \mathrm{~h}$ with or without $1 \mu \mathrm{moll} \mathrm{I}^{-1} \mathrm{GWO} 742$ (b, c) or $3.0 \mu \mathrm{moll}-1$ pioglitazone (d, e) in the presence or absence of GSK0660 or GW9662. (f) The HMC were then incubated for $24 \mathrm{~h}$ with varying concentrations of telmisartan $(0.1,1.0$ or $10 \mu$ mol I-1). (g, h) The $\mathrm{HMC}$ were then incubated for $24 \mathrm{~h}$ with or without telmisartan $\left(10 \mu \mathrm{moll} \mathrm{I}^{-1}\right)$ in the presence or absence of GSK0660 or GW9662. Firefly luciferase activity is shown relative to that of the untreated cells. The results are expressed as the mean \pm s.d. of three or four experiments performed in duplicate ( $n=3-4$ ). NS, not significant, ${ }^{*} P<0.05$ and ${ }^{*} P<0.01$ compared with the cells incubated under the indicated conditions according to one-way ANOVA followed by Scheffe's post hoc test. A full color version of this figure is available at Hypertension Research online.

Telmisartan also reduced the above-mentioned increases in TGF- $\beta 1$ and Collagen IV alpha2 expression, which were restored by GSK0660 (Figures $4 \mathrm{c}$ and $\mathrm{d}$ ). Furthermore, TGF- $\beta 1$-stimulated production of Collagen IV protein (Figure 4e) and PDGF-BB-stimulated HMC proliferation (Figure 4f) were significantly decreased by telmisartan.

We also examined whether angiotensin II and aldosterone were involved in the PAI-1 expression observed in these experiments. In the HMC, angiotensin II and aldosterone did not significantly increase PAI-1 protein production at moderate doses of 0.1 and $1.0 \mathrm{nmoll}^{-1}$ (Figure 4g) and at relatively high doses of 10 and $100 \mathrm{nmoll}^{-1}$
(Figure 4h), respectively. Moreover, eprosartan, a non-PPAR-activating $\mathrm{ARB}$, had no inhibitory effect on $\mathrm{PAI}-1$ protein production stimulated by TGF- $\beta 1$ (Figure $4 \mathrm{i}$ ).

In addition, in the HMC, TGF- $\beta 1\left(25 \mathrm{pg} \mathrm{ml}^{-1}\right)$ increased mRNA PPAR- $\delta$ expression by 1.2 -fold at 3 and $6 \mathrm{~h}$ and PPAR- $\delta$ protein expression by 1.6 -fold at $24 \mathrm{~h}$ (Figures $4 \mathrm{j}$ and $\mathrm{k}$ ). This might have potentiated the inhibitory effect of telmisartan on TGF- $\beta 1$-induced fibrotic changes.

These results indicate that in HMC, telmisartan inhibits TGF- $\beta 1$ induced pro-fibrotic responses in a PPAR- $\delta$-dependent manner, rather than in an angiotensin-blocking manner. 
a

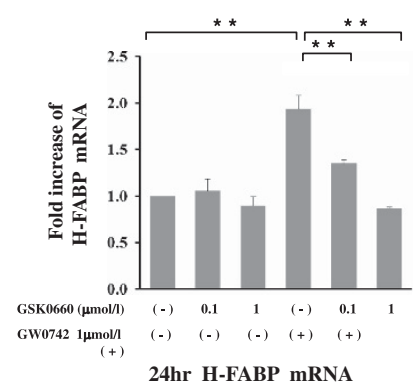

e PPAR $\delta$

$\beta$-actin

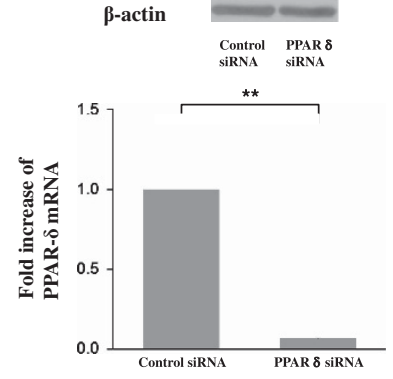

b

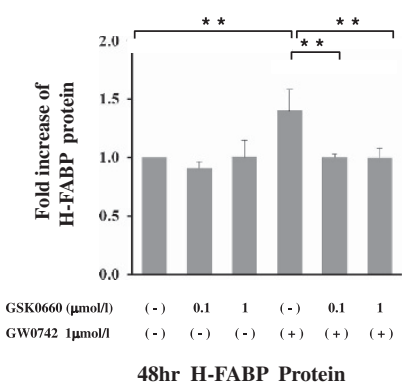

f

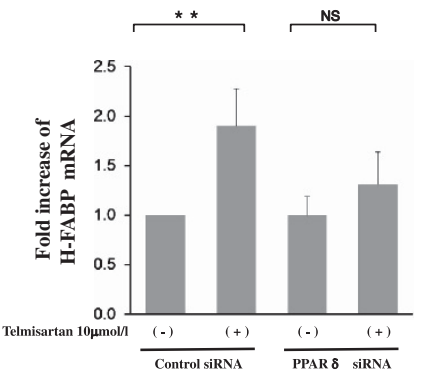

c

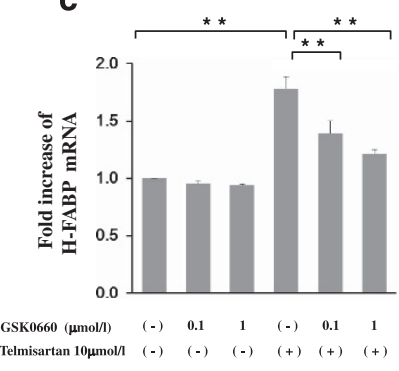

24hr H-FABP mRNA d

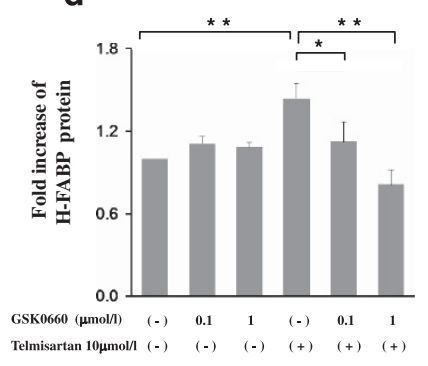

48hr H-FABP Protein

Figure 3 Telmisartan induced heart-type fatty acid-binding protein (H-FABP) and uncoupling protein (UCP)-2 expression in a peroxisome proliferatoractivated receptor (PPAR)- $\delta$-dependent manner in human mesangial cells (HMC). HMC were incubated for $24-48 \mathrm{~h}$ with or without $1 \mu$ mol I-1 GW0742 $(\mathbf{a}, \mathbf{b}, \mathbf{g})$ or $10 \mu \mathrm{mol} \mathrm{I} \mathrm{I}^{-1}$ telmisartan (c, $\mathbf{d}, \mathbf{h}$ ) in the presence or absence of GSK0660. TaqMan real-time PCR for H-FABP (a, c) was performed using cDNA from HMC that had been treated for $24 \mathrm{~h}$. The amounts of H-FABP mRNA were normalized to the $\beta$-actin level. The concentration of H-FABP protein (b, $d$ ) in total cell lysates from HMC that had been treated for $48 \mathrm{~h}$ was determined by ELISA. (e) Representative immunoblot of PPAR- $\delta$ protein (upper panel) and mRNA expression (lower panel) in short interfering RNA (siRNA)-mediated PPAR- $\delta$ knockdown cells and control cells. (f) H-FABP mRNA amounts in siRNA-mediated PPAR- $\delta$ knockdown cells and control cells treated with or without $10-\mu \mathrm{mol}^{-1}$ telmisartan. (g, h) TaqMan real-time PCR for UCP-2 was performed using cDNA from HMC that had been treated for $24 \mathrm{~h}$. The amounts of UCP-2 mRNA were normalized to the $\beta$-actin level. The results are expressed as the mean \pm s.d. of three replicated experiments. NS: not significant, ${ }^{*} P<0.05$ and $* * P<0.01$ compared with cells incubated under the indicated conditions according to one-way ANOVA followed by Scheffe's post hoc test $(\mathbf{a}-\mathbf{d}),(\mathbf{f}-\mathbf{h})$ and the Mann-Whitney test (e). A full color version of this figure is available at Hypertension Research online.

\section{Inhibitory effect of telmisartan on TGF- $\beta 1$-stimulated PAI-1 production is mediated via the PPAR- $\delta$-dependent inactivation of ERK1/2}

As TGF- $\beta 1$ was reported to induce PAI- 1 expression by activating the ERK pathway in $\mathrm{HMC},{ }^{35}$ we focused on the ERK pathway when attempting to clarify the molecular mechanism by which telmisartan inhibits TGF- $\beta 1$-induced PAI- 1 expression. In the HMC, $30 \mathrm{~min}$ pretreatment with PD98059, an inhibitor of a specific ERK activator, MEK1, inhibited the stimulatory effect of TGF- $\beta 1$ on PAI- 1 secretion by about $25 \%$ (Figure $5 \mathrm{a}$ ), while TGF- $\beta 1$ treatment caused a 4.2 -fold increase in ERK1/2 phosphorylation (Figure 5b). Telmisartan treatment significantly reduced the TGF- $\beta 1$-stimulated phosphorylation of ERK1/ 2. Finally, the inhibitory effect of telmisartan on ERK1/2 phosphorylation was completely reversed by GSK0660 (Figure 5b). These results indicated that telmisartan reduced the ERK1/2 phosphorylation induced by TGF- $\beta 1$ in HMC via a PPAR- $\delta$-dependent mechanism.

Taking these results together, telmisartan was demonstrated to diminish TGF- $\beta 1$-induced PAI- 1 expression, at least in part, via the PPAR- $\delta$-mediated reduction in ERK phosphorylation.

\section{DISCUSSION}

In this study, we found that in HMC telmisartan activated endogenous PPAR- $\delta$ and induced the expression of typical PPAR target genes related to fatty acid oxidation (H-FABP and UCP-2). ${ }^{2}$ This target gene induction was dependent on PPAR- $\delta$ but not on PPAR- $\gamma$. These findings support the findings of a recent study in which telmisartan activated PPAR- $\delta$ in vitro and in vivo in rodents ${ }^{27}$. We have also demonstrated that telmisartan inhibited the TGF- $\beta$ stimulated expression of pro-fibrotic factors (PAI-1, TGF- $\beta 1$, connective tissue growth factor and Collagen IV) in HMC in a PPAR- $\delta$-dependent manner partly by reducing ERK phosphorylation. Additionally, telmisartan also inhibited PDGF-BB-stimulated HMC proliferation. To the best of our knowledge, this is the first report to describe these possible anti-fibrotic effects of telmisartan as a PPAR- $\delta$ agonist.

In the current study, the PPAR- $\delta$ activation of telmisartan was verified using specific PPAR- $\delta$ and PPAR- $\gamma$ antagonists and PPAR- $\delta$ gene silencing in HMC. First, the presence of functional PPAR- $\delta$ and PPAR- $\gamma$ proteins was confirmed in HMC. Second, we found that GW0742, an authentic PPAR- $\delta$ agonist, enhanced PPRE-luc activity and that this enhanced activity was inhibited by GSK0660, a specific PPAR- $\delta$ antagonist. Third, we found that pioglitazone, an authentic PPAR- $\gamma$ agonist, enhanced PPRE-luc activity and that the enhanced activity was inhibited by GW9662, a specific PPAR- $\gamma$ antagonist. Finally, telmisartan increased PPRE-luc activity and the expression of the PPAR- $\delta$ target genes H-FABP and UCP-2, and these effects were reversed by PPAR- $\delta$ antagonism and/ or PPAR- $\delta$ gene silencing. These results indicate that telmisartan 
activates PPAR- $\delta$ rather than PPAR- $\gamma$ in HMC, in which both PPAR- $\delta$ and PPAR- $\gamma$ exist as functional proteins. Many studies have revealed that telmisartan activates PPAR- $\gamma$, induces the expression of a variety of target genes ${ }^{15,16}$ and increases insulin sensitivity. ${ }^{21,25}$ As telmisartan is a dual modulator of PPAR- $\delta$ and PPAR- $\gamma$, it might activate PPAR $\delta$ more effectively than PPAR $-\gamma$ by differentially modulating the interactions of specific PPAR with transcriptional cofactors in HMC. In an elegant experimental study involving PPAR- $\gamma$ mutants with mutations in their PPAR- $\gamma$ ligand-binding domains, ${ }^{17}$ the co-activator recruitment and corepressor dissociation of wild-type PPAR- $\gamma$ were more efficiently promoted by TZD (true PPAR- $\gamma$ agonists) than by telmisartan, while telmisartan was more effective at activating the PPAR- $\gamma$ mutants. The transcriptional cofactors were shown to exhibit cellspecific preferences toward different PPAR molecules. ${ }^{36}$ Although its detailed molecular interactions with transcriptional cofactors remain to be clarified, telmisartan might function as a better ligand for PPAR$\delta$ than for PPAR- $\gamma$, especially in HMC. a

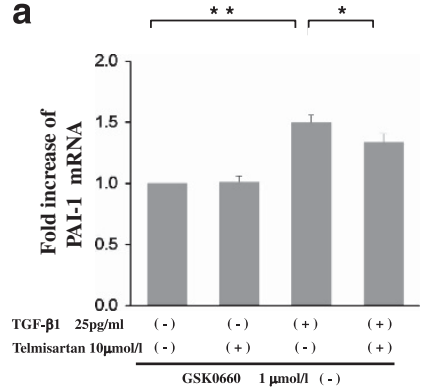

C
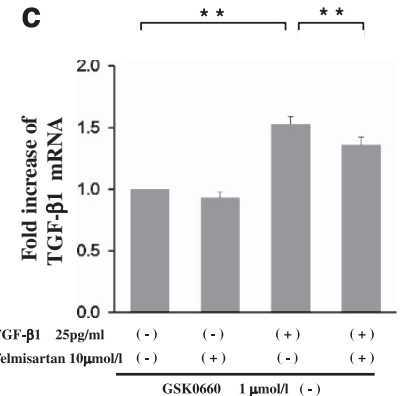

e

TypeIV collagen

$\beta$-actin

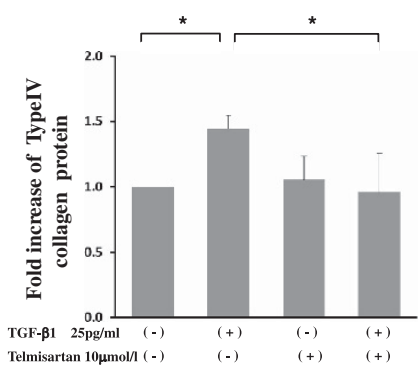

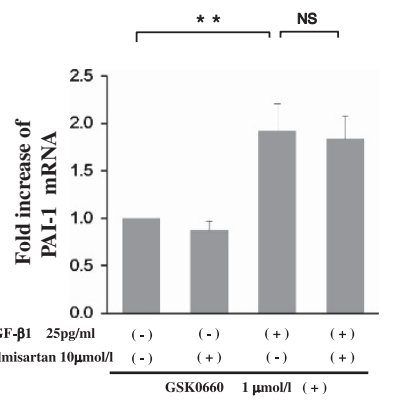

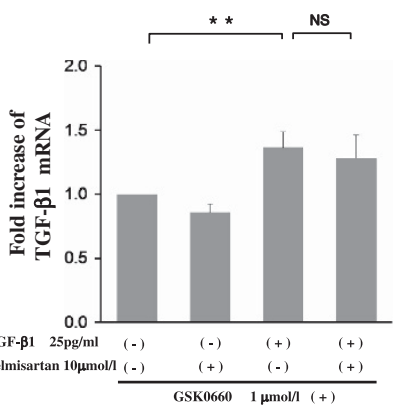

b

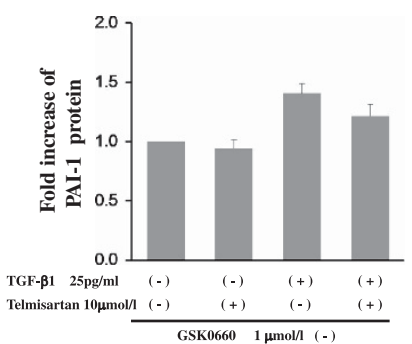

d
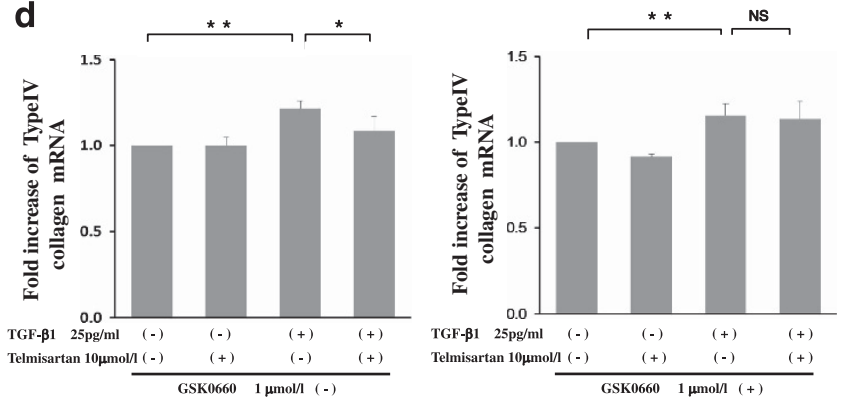
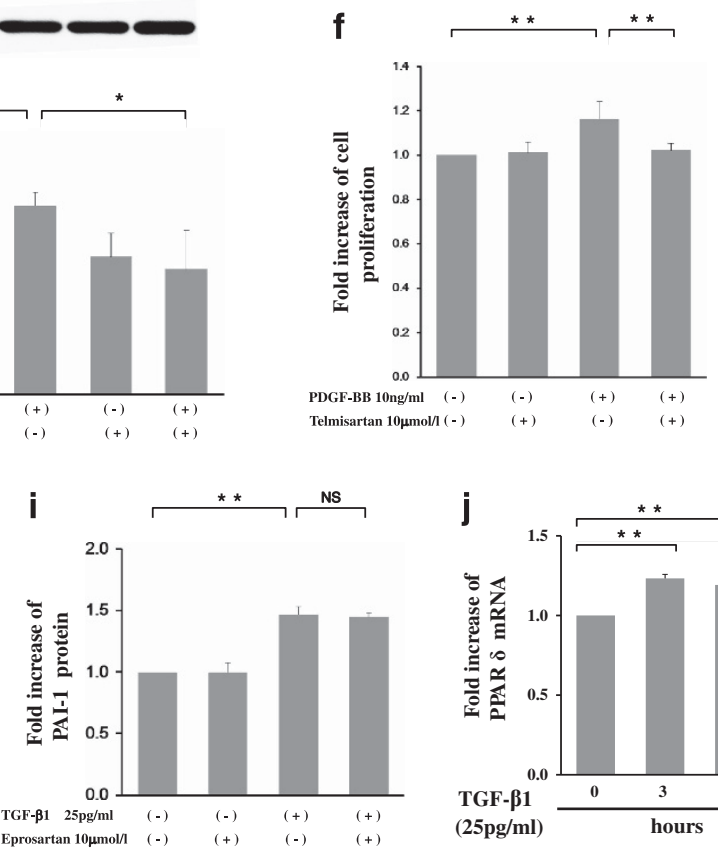

g

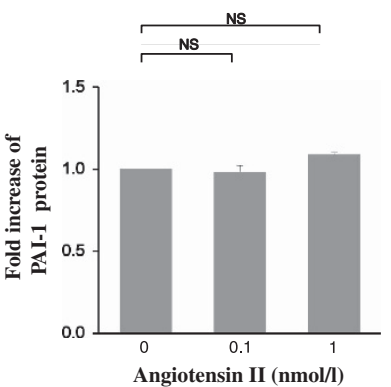

h

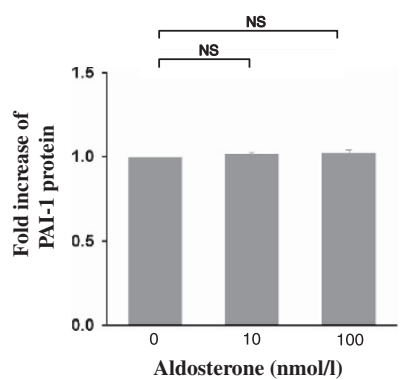

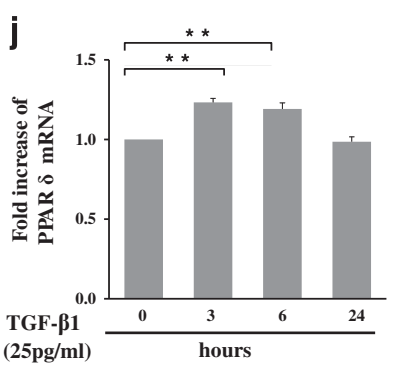

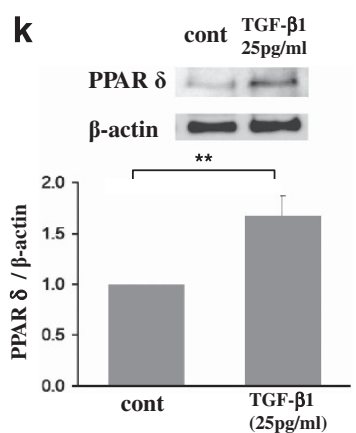

24hr PPAR $\delta$ Protein 
In HMC, telmisartan induced the expression of PPAR- $\delta$ target genes related to fatty acid oxidation (H-FABP and UCP-2) in a PPAR$\delta$-dependent manner. PPAR- $\delta$ enhances fatty acid catabolism and energy uncoupling in skeletal muscle by upregulating the expression of H-FABP, UCP-2 and UCP-3, ${ }^{2,37}$ which probably leads to increased insulin sensitivity and endurance and reduced weight gain. The local expression and activation of PPAR- $\delta$ reduces the lipid burden and might protect against lipotoxicity caused by ectopic lipid deposition in non-adipose tissues. ${ }^{38}$ As for the kidney, lipid accumulation and the subsequent renal lipotoxicity are considered to enhance renal dysfunction. ${ }^{39}$ However, the activation of PPAR- $\alpha$, another enhancer of fatty acid catabolism, reduced the glomerular lipid accumulation and glomerular fibrosis induced in mice fed a high fat diet. ${ }^{40}$ PPAR- $\delta$ activation might also reduce renal damage by enhancing lipolysis, resulting in decreased lipid deposition. Therefore, as a PPAR- $\delta$ agonist telmisartan might reduce renal damage, at least in part, by promoting fatty acid oxidation.

Another major finding of the current study was our demonstration of the anti-fibrotic effects of telmisartan, which were induced via PPAR- $\delta$ activation, in HMC. Telmisartan reduced the TGF- $\beta 1$ stimulated expression of PAI-1, TGF- $\beta 1$ and Collagen IV alpha 2 in a PPAR- $\delta$-dependent manner in HMC. The induction of PAI- 1 expression by TGF- $\beta$ was partly mediated by ERK phosphorylation, and this phosphorylation was weakened by telmisartan in a PPAR- $\delta$ dependent manner. Since telmisartan was identified as a partial PPAR$\gamma$ activator in 2004, many studies have examined whether it exerts anti-inflammatory effects via PPAR- $\gamma$ activation. ${ }^{18-20,23,24,29,41}$ In previous studies, telmisartan inhibited the inflammation elicited by
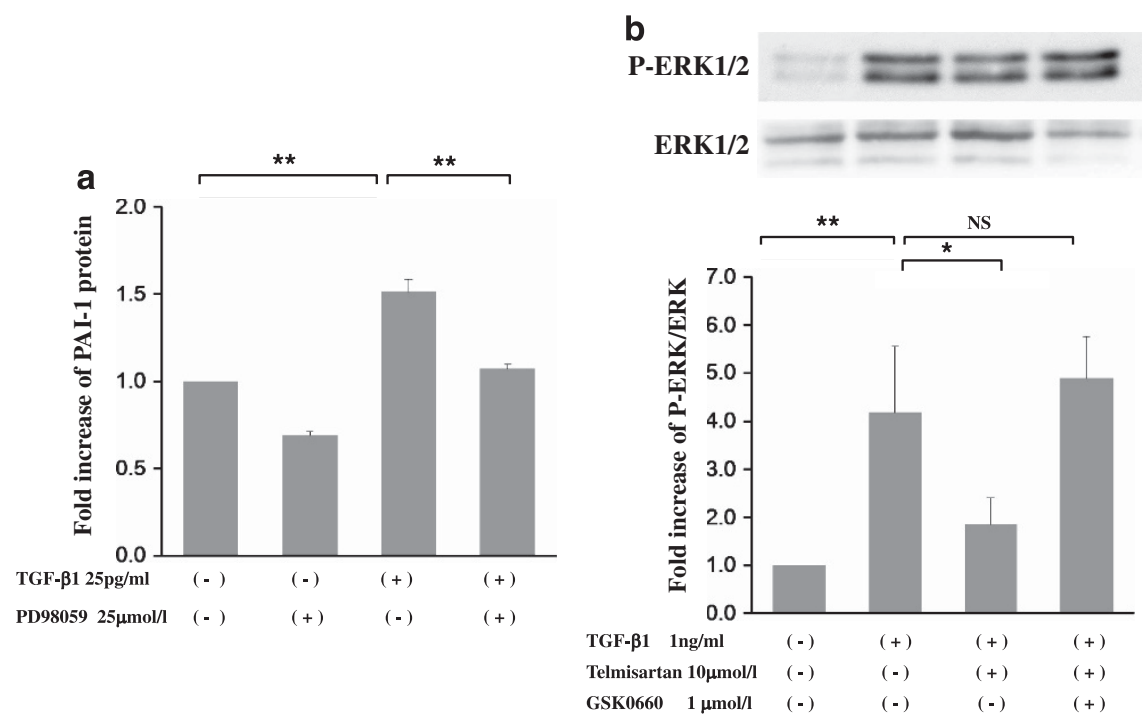

Figure 5 The inhibitory effect of telmisartan on transforming growth factor (TGF)- $\beta 1$-stimulated plasminogen activator inhibitor (PAI)-1 production is mediated by the peroxisome proliferator-activated receptor (PPAR)- $\delta$-dependent inactivation of extracellular signal-regulated kinase (ERK) $1 / 2$. (a) Human mesangial cells (HMC) were incubated with TGF- $\beta 1\left(25 \mathrm{pg} \mathrm{ml}^{-1}\right)$ for $24 \mathrm{~h}$ in the presence or absence of PD98059 $\left(25 \mu \mathrm{mol} \mathrm{I}^{-1}\right)$. The PAI-1 concentrations of the supernatants were determined by an immunoassay. The concentration of PAI-1 protein in the supernatant of the untreated cells was defined as 1.0. (b) HMC were incubated for $30 \mathrm{~min}$ with vehicle alone, TGF- $\beta 1\left(25 \mathrm{pg} \mathrm{ml}^{-1}\right)$ alone, TGF- $\beta 1$ plus telmisartan $\left(10 \mu \mathrm{moll} \mathrm{I}^{-1}\right)$, or TGF- $\beta 1$ plus telmisartan plus GSK0660 $\left(1 \mu \mathrm{moll} \mathrm{I}^{-1}\right)$. Total ERK and phosphorylated ERK (pERK) in whole-cell lysates from untreated or treated HMC were detected by immunoblot (upper panel). The pERK-to-total ERK ratio of the untreated cells was defined as 1.0 (lower panel). The results are shown as the mean \pm s.d. of three replicated experiments $(n=3)$. NS: not significant, ${ }^{*} P<0.05$ and ${ }^{* *} P<0.01$ compared with cells incubated under the indicated conditions according to one-way ANOVA followed by Scheffe's post hoc test. A full color version of this figure is available at Hypertension Research online.

Figure 4 Telmisartan reduced the transforming growth factor (TGF)- $\beta 1$-induced expression of pro-fibrotic genes in a peroxisome proliferator-activated receptor (PPAR)- $\delta$-dependent manner. (a-c) Human mesangial cells (HMC) were incubated with vehicle alone, TGF- $\beta 1$ (25 pg ml-1) alone, telmisartan $\left(10 \mu \mathrm{moll}^{-1}\right)$ alone, or TGF- $\beta 1$ plus telmisartan for $6(\mathbf{a}, \mathbf{c}), 24 \mathrm{~h} \mathrm{(b,} \mathrm{d)} \mathrm{or} 48 \mathrm{~h}(\mathbf{e})$ in the presence or absence of GSKO660 $\left(1 \mu \mathrm{mol} \mathrm{I}^{-1}\right)$. TaqMan real-time PCR for plasminogen activator inhibitor (PAI)-1 (a), TGF- $\beta 1$ (c) and Collagen IV alpha2 (d) were performed using cDNA from HMC that had been thus treated. The mRNA amounts of each gene were normalized to the $\beta$-actin level. (b) The PAI-1 concentrations of the supernatants were determined by an immunoassay. The mRNA levels of each gene in the untreated control cells and the PAI-1 protein concentrations of the untreated control cell supernatant were defined as 1.0. (e) Collagen IV alpha2 in total cell lysates from HMC was detected by immunoblotting (upper panel). The ratio of collagen IV alpha2 to $\beta$-actin in the untreated cells was defined as 1.0 (lower panel). (f) Proliferation status of HMC treated with different reagents was evaluated by XTT assay and the data of HMC treated with only vehicle were defined as 1.0. $(\mathbf{g}, \mathbf{h}) \mathrm{HMC}$ were incubated with different concentrations of angiotensin II (0, 0.1 or $1 \mathrm{nmoll} \mathrm{I}^{-1}$ ) or aldosterone $\left(0,10\right.$ or $\left.100 \mathrm{nmolI}^{-1}\right)$ for $24 \mathrm{~h}$. The PAI-1 concentrations of the supernatants were determined using an immunoassay. (i) HMC were incubated with or without TGF- $\beta 1\left(25 \mathrm{pg} \mathrm{ml}^{-1}\right)$ for $24 \mathrm{~h}$ in the presence or absence of eprosartan $\left(10 \mu \mathrm{mol} \mathrm{I}^{-1}\right)$. The PAI-1 concentrations of the supernatants were determined by an immunoassay. (j) HMC were incubated with TGF- $\beta 1\left(25 \mathrm{pg} \mathrm{ml}^{-1}\right.$ ) for $0,3,6$ or $24 \mathrm{~h}$. The TaqMan real-time PCR for peroxisome proliferator-activated receptor (PPAR)- $\delta$ was performed using cDNA from HMC that had been treated for the indicated hours. The mRNA expression levels of each gene were normalized to the $\beta$-actin level. (k) The PPAR- $\delta$ protein mounts were measured by immunoblotting (upper panel). The ratio of PPAR- $\delta$ to $\beta$-actin in the untreated cells was defined as 1.0 (lower panel). The results are shown as the mean $\pm s$.d. of three to five replicated experiments $(n=3-5)$. NS: not significant, ${ }^{*} P<0.05$ and ${ }^{*} P<0.01$ compared with the cells incubated under the indicated conditions according to oneway ANOVA followed by Scheffe's post hoc test $(\mathbf{a}-\mathbf{j})$ and the Mann-Whitney test (k). A full color version of this figure is available at Hypertension Research online. 
pro-inflammatory factors by activating PPAR- $\gamma$, which inhibited NF-kB expression in human vascular smooth muscle cells ${ }^{18}$ and human monocytes ${ }^{19}$ or led to the induction of hepatocyte growth factor, a well-known anti-inflammatory and anti-fibrotic factor, and the prevention of renal fibrosis in mice with obstructive nephropathy. ${ }^{20}$ Telmisartan-activated PPAR- $\gamma$ also improved vascular inflammation in subtotal nephrectomized rats ${ }^{29}$ and glomerular damage in immune-mediated renal injury. ${ }^{41}$ On the contrary, telmisartan reportedly ameliorated vascular inflammation in a PPAR- $\gamma$-independent manner. ${ }^{23,24}$ In several animal experiments, telmisartan prevented renal fibrosis. ${ }^{42,43}$ Telmisartan attenuated renal interstitial fibrosis in acatalasemic mice with obstructive nephropathy, ${ }^{42}$ and ameliorated glomerulosclerosis in rats with progressive anti-Thyl.1 nephritis, ${ }^{43}$ although it remained unclear whether the renoprotective effects were mediated by PPAR- $\gamma$ or $\delta$ action. As for PPAR- $\delta$, authentic PPAR- $\delta$ agonists are known to exert anti-inflammatory effects. ${ }^{9,10}$ GW501516, a representative PPAR- $\delta$ agonist, prevents tumor necrosis factor- $\alpha$-induced NF-kB activation in human keratinocytes by reducing p65 acetylation through $5^{\prime}$ adenosine monophosphate-activated protein kinase. ${ }^{9}$ GW501516 also prevents fatty acid-induced NF-kB activation in skeletal muscle cells. ${ }^{10}$ In addition, a previous study suggested that the agonist-induced phosphorylation of $5^{\prime}$ adenosine monophosphate-activated protein kinase-1 might reduce ERK activation via mutual interactions. ${ }^{44}$ Furthermore, in adipose tissue, PPAR- $\delta$ reduction or knockout caused increased ERK phosphorylation, ${ }^{45}$ as well as the downregulation of PPAR- $\delta$ target genes. More recently, PPAR- $\delta$ suppression has been shown to promote phosphorylation of p38MAPK and collagen IV secretion. ${ }^{46}$ According to these recent findings, PPAR- $\delta$ itself or PPAR- $\delta$ activation probably diminishes inflammatory signalling, including ERK or p38MAPK phosphorylation. Therefore, it seems likely that telmisartan-activated PPAR- $\delta$ was at least partially involved in the reduced ERK activation and ensuing PAI-1 reduction observed in the current study, although the detailed molecular mechanism responsible for the observed effects remains unclear.

Finally, our preliminary immunohistochemical analysis using renal biopsy samples from patients with IgA nephropathy $(n=10)$ showed that PPAR- $\delta$ expression was significantly greater in mildly to moderately proliferative glomerulonephritis than in minor proliferative ones (Figure 1e). Considering the anti-fibrotic of PPAR- $\delta$ activation, PPAR- $\delta$ may take a renoprotective role in early to middle stages of progressive proliferative glomerulonephritis such as IgA nephritis, although further detailed studies will be required in future.

In summary, the current study revealed that in HMC, telmisartan activated endogenous PPAR- $\delta$ and thereby not only enhanced the expression of PPAR- $\delta$ target genes but also exerted anti-fibrotic effects in a PPAR- $\delta$-dependent manner. Our data suggest that telmisartan could be useful for the clinical management of hypertensive patients with chronic kidney disease, in whom vicious cycles of lipotoxicity occasionally develop.

\section{ACKNOWLEDGEMENTS}

This study was supported by Grants-in-Aid for Scientific Research (c) (No 21591024 and No. 24591193) and Grants-in-Aid for Scientific Research (b) (No. 24390216) from the Japan Society for the Promotion of Science. The results presented in this paper have not been published previously in whole or part, except in an abstract form, and the paper is not under consideration of any other journals.
1 Guan Y, Breyer MD. Peroxisome proliferator-activated receptors (PPARs): novel therapeutic targets in renal disease. Kidney Int 2001; 60: 14-30.

2 Barish GD, Narkar VA, Evans RM. PPAR delta: a dagger in the heart of the metabolic syndrome. J Clin Invest 2006; 116: 590-597.

3 Neher MD, Weckbach S, Huber-Lang MS, Stahel PF. New insights into the role of peroxisome proliferator-activated receptors in regulating the inflammatory response after tissue injury. PPAR Res 2012; 2012: 728461.

4 Stienstra R, Duval C, Muller M, Kersten S. PPARs, obesity, and inflammation. PPAR Res 2007; 2012: 95974.

5 Guan Y. Peroxisome proliferator-activated receptor family and its relationship to renal complications of the metabolic syndrome. J Am Soc Nephrol 2004; 15 2801-2815.

6 Zandbergen F, Plutzky J. PPARalpha in atherosclerosis and inflammation. Biochim Biophys Acta 2007; 1771: 972-982.

7 Jiang C, Ting AT, Seed B. PPAR-gamma agonists inhibit production of monocyte inflammatory cytokines. Nature 1998; 391: 82-86.

8 Lee $\mathrm{CH}$, Chawla A, Urbiztondo N, Liao D, Boisvert WA, Evans RM, Curtiss LK. Transcriptional repression of atherogenic inflammation: modulation by PPARdelta. Science 2003; 302: 453-457.

9 Barroso E, Eyre E, Palomer X, Vazquez-Carrera M. The peroxisome proliferator-activated receptor beta/delta (PPARbeta/delta) agonist GW501516 prevents TNF-alpha-induced NF-kappaB activation in human HaCaT cells by reducing p65 acetylation through AMPK and SIRT1. Biochem Pharmacol 2011; 81: 534-543.

10 Coll T, Alvarez-Guardia D, Barroso E, Gomez-Foix AM, Palomer X, Laguna JC, VazquezCarrera M. Activation of peroxisome proliferator-activated receptor-\{delta\} by GW501516 prevents fatty acid-induced nuclear factor-\{kappa\}B activation and insulin resistance in skeletal muscle cells. Endocrinology 2010; 151: 1560-1569.

11 de Gasparo M, Catt KJ, Inagami T, Wright JW, Unger T. International union of pharmacology. XXIII. The angiotensin II receptors. Pharmacol Rev 2000; 52: 415-472.

12 Dahlof B, Devereux RB, Kjeldsen SE, Julius S, Beevers G, de Faire U, Fyhrquist F, Ibsen H, Kristiansson K, Lederballe-Pedersen O, Lindholm LH, Nieminen MS, Omvik P, Oparil S, Wedel H, Group LS. Cardiovascular morbidity and mortality in the Losartan Intervention For Endpoint reduction in hypertension study (LIFE): a randomised trial against atenolol. Lancet 2002; 359: 995-1003.

13 Henriksen EJ, Jacob S, Kinnick TR, Teachey MK, Krekler M. Selective angiotensin II receptor antagonism reduces insulin resistance in obese Zucker rats. Hypertension 2001; 38: 884-890.

14 Furuhashi M, Ura N, Higashiura K, Murakami H, Tanaka M, Moniwa N, Yoshida D, Shimamoto K. Blockade of the renin-angiotensin system increases adiponectin concentrations in patients with essential hypertension. Hypertension 2003; 42: 76-81.

15 Schupp M, Janke J, Clasen R, Unger T, Kintscher U. Angiotensin type 1 receptor blockers induce peroxisome proliferator-activated receptor-gamma activity. Circulation 2004; 109: 2054-2057.

16 Benson SC, Pershadsingh $\mathrm{HA}, \mathrm{Ho} \mathrm{Cl}$, Chittiboyina A, Desai P, Pravenec M, Qi N, Wang J, Avery MA, Kurtz TW. Identification of telmisartan as a unique angiotensin II receptor antagonist with selective PPARgamma-modulating activity. Hypertension 2004; 43: 993-1002.

17 Tagami T, Yamamoto H, Moriyama K, Sawai K, Usui T, Shimatsu A, Naruse M. A selective peroxisome proliferator-activated receptor-gamma modulator, telmisartan, binds to the receptor in a different fashion from thiazolidinediones. Endocrinology 2009; 150: 862-870.

18 Tian Q, Miyazaki R, Ichiki T, Imayama I, Inanaga K, Ohtsubo H, Yano K, Takeda K, Sunagawa K. Inhibition of tumor necrosis factor-alpha-induced interleukin-6 expression by telmisartan through cross-talk of peroxisome proliferator-activated receptorgamma with nuclear factor kappaB and CCAAT/enhancer-binding protein-beta. Hypertension 2009; 53: 798-804.

19 Pang T, Benicky J, Wang J, Orecna M, Sanchez-Lemus E, Saavedra JM. Telmisartan ameliorates lipopolysaccharide-induced innate immune response through peroxisome proliferator-activated receptor-gamma activation in human monocytes. $J$ Hypertens 2012; 30: 87-96.

20 Kusunoki H, Taniyama Y, Azuma J, lekushi K, Sanada F, Otsu R, Iwabayashi M, Okayama K, Rakugi H, Morishita R. Telmisartan exerts renoprotective actions via peroxisome proliferator-activated receptor-gamma/hepatocyte growth factor pathway independent of angiotensin II type 1 receptor blockade. Hypertension 2012; 59: 308-316.

21 Benndorf RA, Rudolph T, Appel D, Schwedhelm E, Maas R, Schulze F, Silberhorn E, Boger $\mathrm{RH}$. Telmisartan improves insulin sensitivity in nondiabetic patients with essential hypertension. Metabolism 2006; 55: 1159-1164.

22 Yamamoto K, Ohishi M, Ho C, Kurtz TW, Rakugi H. Telmisartan-induced inhibition of vascular cell proliferation beyond angiotensin receptor blockade and peroxisome proliferator-activated receptor-gamma activation. Hypertension 2009; 54: 1353-1359.

23 Cianchetti S, Del Fiorentino A, Colognato R, Di Stefano R, Franzoni F, Pedrinelli R. Anti-inflammatory and anti-oxidant properties of telmisartan in cultured human umbilical vein endothelial cells. Atherosclerosis 2008; 198: 22-28.

24 Nakano A, Hattori Y, Aoki C, Jojima T, Kasai K. Telmisartan inhibits cytokine-induced nuclear factor-kappaB activation independently of the peroxisome proliferator-activated receptor-gamma. Hypertens Res 2009; 32: 765-769.

25 Unger T, Stoppelhaar M. Rationale for double renin-angiotensin-aldosterone system blockade. Am J Cardiol 2007; 100: 25J-31J. 
26 Granberry MC, Hawkins JB, Franks AM. Thiazolidinediones in patients with type 2 diabetes mellitus and heart failure. Am J Health Syst Pharm 2007; 64: 931-936.

$27 \mathrm{He} \mathrm{H}$, Yang D, Ma L, Luo Z, Ma S, Feng X, Cao T, Yan Z, Liu D, Tepel M, Zhu Z. Telmisartan prevents weight gain and obesity through activation of peroxisome proliferator-activated receptor-delta-dependent pathways. Hypertension 2010; 55: 869-879.

28 Li L, Luo Z, Yu H, Feng X, Wang P, Chen J, Pu Y, Zhao Y, He H, Zhong J, Liu D, Zhu Z. Telmisartan improves insulin resistance of skeletal muscle through peroxisome proliferator-activated receptor-delta activation. Diabetes 2013; 62: 762-774.

29 Toba H, Tojo C, Wang J, Noda K, Kobara M, Nakata T. Telmisartan inhibits vascular dysfunction and inflammation via activation of peroxisome proliferator-activated receptor-gamma in subtotal nephrectomized rat. Eur J Pharmacol 2012; 685: 91-98.

30 Chen Y, Luo Q, Xiong Z, Liang W, Chen L, Xiong Z. Telmisartan counteracts TGF-beta1 induced epithelial-to-mesenchymal transition via PPAR-gamma in human proximal tubule epithelial cells. Int J Clin Exp Pathol 2012; 5: 522-529.

31 Bakris G, Burgess E, Weir M, Davidai G, Koval S, Investigators AS. Telmisartan is more effective than losartan in reducing proteinuria in patients with diabetic nephropathy. Kidney Int 2008; 74: 364-369.

32 Ladino M, Hernandez Schulman I. Renovascular and renoprotective properties of telmisartan: clinical utility. Int J Nephrol Renovasc Dis 2010; 3: 33-38.

33 Kimura H, Li X, Torii K, Okada T, Takahashi N, Fujii H, Ishihara S, Yoshida H. A natural PPAR-gamma agonist, 15-deoxy-delta 12,14-prostaglandin J2, may act as an enhancer of PAI-1 in human proximal renal tubular cells under hypoxic and inflammatory conditions. Nephrol Dial Transplant 2008; 23: 2496-2503.

34 Ono T, Sogabe M, Ogura M, Furusaki F. Automated latex photometric immunoassay for total plasminogen activator inhibitor-1 in plasma. Clin Chem 2003; 49: 987-989.

35 Hong HK, Song CY, Kim BC, Lee HS. ERK contributes to the effects of Smad signaling on oxidized LDL-induced PAI-1 expression in human mesangial cells. Trans/ Res 2006; 148: $171-179$.

36 Lim HJ, Moon I, Han K. Transcriptional cofactors exhibit differential preference toward peroxisome proliferator-activated receptors alpha and delta in uterine cells. Endocrinology 2004; 145: 2886-2895.

37 Furuhashi M, Hotamisligil GS. Fatty acid-binding proteins: role in metabolic diseases and potential as drug targets. Nat Rev Drug Discov 2008; 7: 489-503.
38 Reilly SM, Lee CH. PPAR delta as a therapeutic target in metabolic disease. FEBS Lett 2008; 582: 26-31.

39 Bobulescu IA. Renal lipid metabolism and lipotoxicity. Curr Opin Nephrol Hypertens 2010; 19: 393-402.

40 Tanaka Y, Kume S, Araki S, Isshiki K, Chin-Kanasaki M, Sakaguchi M, Sugimoto T, Koya D, Haneda M, Kashiwagi A, Maegawa H, Uzu T. Fenofibrate, a PPARalpha agonist, has renoprotective effects in mice by enhancing renal lipolysis. Kidney Int 2011; 79: 871-882.

41 Hamano Y, Okude T, Yokosuka O, Ogawa M. Attenuation of immune-mediated renal injury by telmisartan, an angiotensin receptor blocker and a selective PPAR-gamma activator. Nephron Extra 2011; 1: 78-90.

42 Sugiyama H, Kobayashi M, Wang DH, Sunami R, Maeshima Y, Yamasaki Y, Masuoka N, Kira S, Makino H. Telmisartan inhibits both oxidative stress and renal fibrosis after unilateral ureteral obstruction in acatalasemic mice. Nephrol Dial Transplant 2005; 20: 2670-2680.

43 Villa L, Boor P, Konieczny A, Kunter U, van Roeyen CR, Denecke B, Gan L, Neusser MA, Cohen CD, Consortium E, Eitner F, Scholl T, Ostendorf T, Floege J. Late angiotensin II receptor blockade in progressive rat mesangioproliferative glomerulonephritis: new insights into mechanisms. J Pathol 2013; 229: 672-684.

44 Barroso E, Rodriguez-Calvo R, Serrano-Marco L, Astudillo AM, Balsinde J, Palomer X, Vazquez-Carrera M. The PPARbeta/delta activator GW501516 prevents the downregulation of AMPK caused by a high-fat diet in liver and amplifies the PGC-1alphaLipin 1-PPARalpha pathway leading to increased fatty acid oxidation. Endocrinology 2011; 152: 1848-1859.

45 Rodriguez-Calvo R, Serrano L, Coll T, Moullan N, Sanchez RM, Merlos M, Palomer X, Laguna JC, Michalik L, Wahli W, Vazquez-Carrera M. Activation of peroxisome proliferator-activated receptor beta/delta inhibits lipopolysaccharide-induced cytokine production in adipocytes by lowering nuclear factor-kappaB activity via extracellular signal-related kinase 1/2. Diabetes 2008; 57: 2149-2157.

46 Yan Z, Ni Y, Wang P, Chen J, He H, Sun J, Cao T, Chen J, Zhao Z, Luo Z, Chen L, Liu D, Zhu Z. Peroxisome proliferator-activated receptor delta protects against obesity-related glomerulopathy through the P38 MAPK pathway. Obesity 2013; 21: $538-545$. 